\title{
Changing life expectancy in Romania after the transition
}

\author{
C Dolea, E Nolte, M McKee
}

J Epidemiol Community Health 2002;56:444-449

See end of article for authors' affiliations

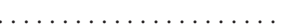

Correspondence to: Professor M McKee, European Centre on Health of Societies in Transition, London School of Hygiene and Tropical Medicine, Keppel Street, London WC1E 7HT, UK; Martin.McKee@Ishtm.ac.uk

Accepted for publication 17 October 2001

\begin{abstract}
Background: While Poland, Hungary, and the Czech Republic have seen impressive gains in life expectancy in the 1990s, Romania has not. In contrast with the other countries, there has been very little research on the causes of the pattern of mortality seen in Romania.

Objectives: To describe the trends in life expectancy at birth in Romania after the political transition in 1989 and to evaluate the contribution of deaths from different causes and different ages to these changes.

Methods: Decomposition of life expectancy by age and cause of death using routine data on mortality for the years 1990, 1996, and 1998; comparison of death rates by age, sex, and cause of death.

Results: Romania has experienced an overall decline of 1.71 years of life expectancy at birth from 1990 to 1996 in men and 0.54 years in women. The major contribution to this decline was an increase in mortality from cardiovascular diseases and diseases of the digestive system, in particular cirrhosis, among the middle aged and elderly. The recovery observed in 1998, of 1.12 years in men and 0.89 years in women, was mainly caused by a reduction in deaths from cardiovascular disease in the middle aged and elderly. Infant and early childhood mortality fell throughout the period but there was an increase of approximately $40 \%$ in mortality at age 5-9 that was almost entirely attributable to AIDS.

Conclusion: This is the first Romanian study that describes the evolution of life expectancy after transition. Romania may at last be beginning to follow the path of improving adult mortality seen in the early 1990s in some of its neighbours. It has, however, been unique in eastern Europe in experiencing increasing childhood mortality. This is attributable to an epidemic of paediatric AIDS, consequent on the tragically inappropriate policies adopted in the 1980s.
\end{abstract}

ri he countries of Central and Eastern European have experienced very different changes in life expectancy since the transition to democracy. Poland, East Germany, Slovakia, and the Czech Republic experienced a marked improvement after 1990. Hungary also experienced an improvement, although it was delayed until 1993. The countries of the former Soviet Union experienced a rapid decline after the late 1980s, before improving after 1994. Finally, in Romania and Bulgaria, life expectancy declined in the late 1980s and early 1990s, only beginning to improve slightly after 1996.

Previous work has looked at some of these changes, in both the late $1980 \mathrm{~s}^{1}$ and early 1990s. ${ }^{2-6}$ This work has, however, been limited to a small number of countries. This is the first study to focus on Romania in the 1990s. It examines trends of life expectancy at birth since the political transition, looking in detail at the contribution to overall life expectancy of specific causes of death among men and women at different ages.

\section{METHODS}

Initial exploration of trends was undertaken using the World Health Organisation's Health for All database. ${ }^{7}$ This confirmed a broadly downward trend in life expectancy at birth between the first post-revolution year, 1990, and 1996, after which an improvement began. Although life expectancy at birth in Romania reached its highest value in 1991, the standardised death rates for men and women were higher in 1990 (the difference being attributable to the distribution of deaths by age), and as 1990 was the first year after transition, for the purpose of this analysis we chose the year 1990 as baseline. Subsequent analyses used population and mortality data from the WHO mortality files for Romania to look at the periods of decline and recovery, comparing 1990, 1996, and 1998. ${ }^{8}$ The data files contain population and deaths as classified by the
International Classification of Disease (ICD-9), by sex and five years age band (with infant deaths listed separately). Causes of death were aggregated into eight major groups: infectious diseases, malignant neoplasms, disease of circulatory system, diseases of respiratory system, diseases of digestive system, external causes and other causes. Age standardised death rates were calculated by the direct method, using the European Standard Population.' Chiang's method for constructing life tables was used to calculate life expectancy at birth in each year. ${ }^{10}$ This gives slightly different results to those in the World Health Organisation's Health for All database, which uses a different method (Wiesler's method) (Remis Prokhorskas, personal communication). Differences in life expectancy observed between 1990 to 1996, and 1996 to 1998 were decomposed by age, sex, and cause of death, based on the approach by Arriaga. ${ }^{11}$ This method allows us to examine the contribution of each cause of death and age group to the overall difference in life expectancy.

\section{RESULTS}

Trends in life expectancy at birth in Romania in the past three decades are shown in figure 1 . After an improvement of about two years in the early 1970s there was a period of stagnation until the mid-1980s. In the late 1980s, however, there was a slight increase in life expectancy at birth, reaching its highest point in 1991 at 66.9 years for men and 73.4 years for women. This was followed by a steady decline until 1996, after which a slight improvement began. By 1998, however, it had still not reached the level in 1991. The decline in overall life expectancy in Romania between 1990 and 1996 was mainly attributable to increased mortality in men, as female life expectancy at birth remained relatively stable, at around 73.3 years. Consequently the male:female gap also increased, from 6.5 years in 1990 to 7.7 years in 1996, falling to 7.5 years in 1998 . 


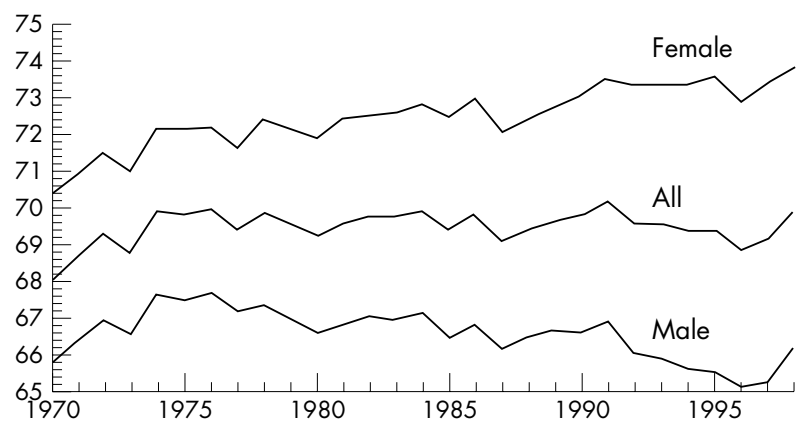

Figure 1 Trends of life expectancy in Romania, 1970-1998. Source: WHO HFA database

\section{Changes in death rates}

The changes in death rates were not the same at all ages. Figure 2 shows the ratio of death rates in each age group in 1996 and 1998, relative to that in 1990 . The death rate among those aged 5-9 increased by 40\% between 1990 and 1996 and remained at about this level through 1998. In contrast, there was a substantial and persistent fall in deaths among younger children. The second age group to experience an increase in mortality was those over 40. In men and women aged 40-44 years, in whom the increase was greatest, there were increases of $41 \%$ and $17 \%$ respectively. By 1998, death rates in this age group had fallen slightly, with a return to the 1990 level among women.
A full understanding of the changes requires examination of how different causes of death have changed in this period. Table 1 shows the standardised death rates for major categories of causes of death in 1990, 1996, and 1998, as well as the ratio of death rates in 1996 and 1998 to those in 1990 . There was a 15\% increase in the all cause age standardised death rate for men in 1996 compared with 1990; for women the corresponding figure was $7 \%$. Among men, the greatest increase was in deaths due to diseases of the digestive system, which were still 39\% higher in 1998. The age standardised death rate from infectious and parasitic diseases also increased substantially in the first period, by $35 \%$, but the overall increase by 1998 had fallen to $20 \%$. Other causes showing increases included deaths from diseases of the circulatory system and cancer. In contrast, death rates from respiratory diseases declined by about one third and from external causes by about $10 \%$.

\section{Contribution of different causes of death to changes in life expectancy}

The following section brings these findings together to assess the contribution of deaths at different ages and from different causes to the changes observed in life expectancy in 1996 and 1998 relative to 1990. Figure 3 shows the breakdown of causes and age at death to the overall change between 1990 and 1996 while figure 4 shows the same information for the period 1996 to 1998 . The sum of values, negative and positive, represents the gap in life expectancy at birth in years. Bars extending

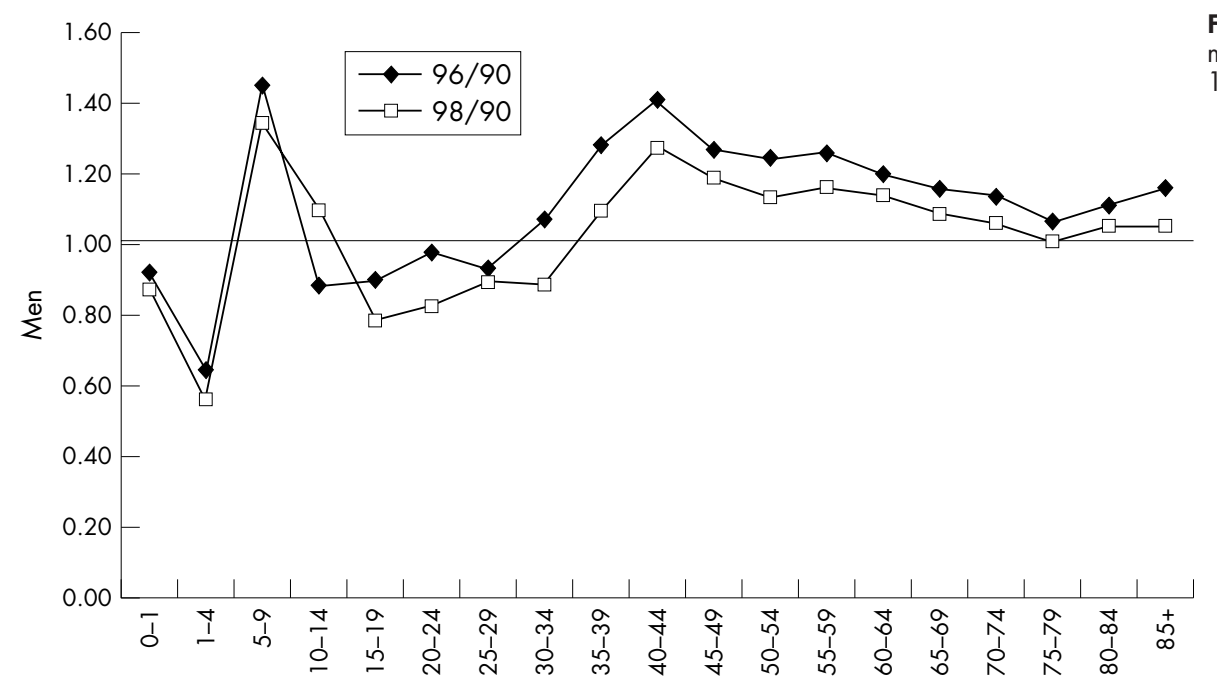

Figure 2 Changes in age specific mortality in Romania: 1990-1996, 1990-1998.

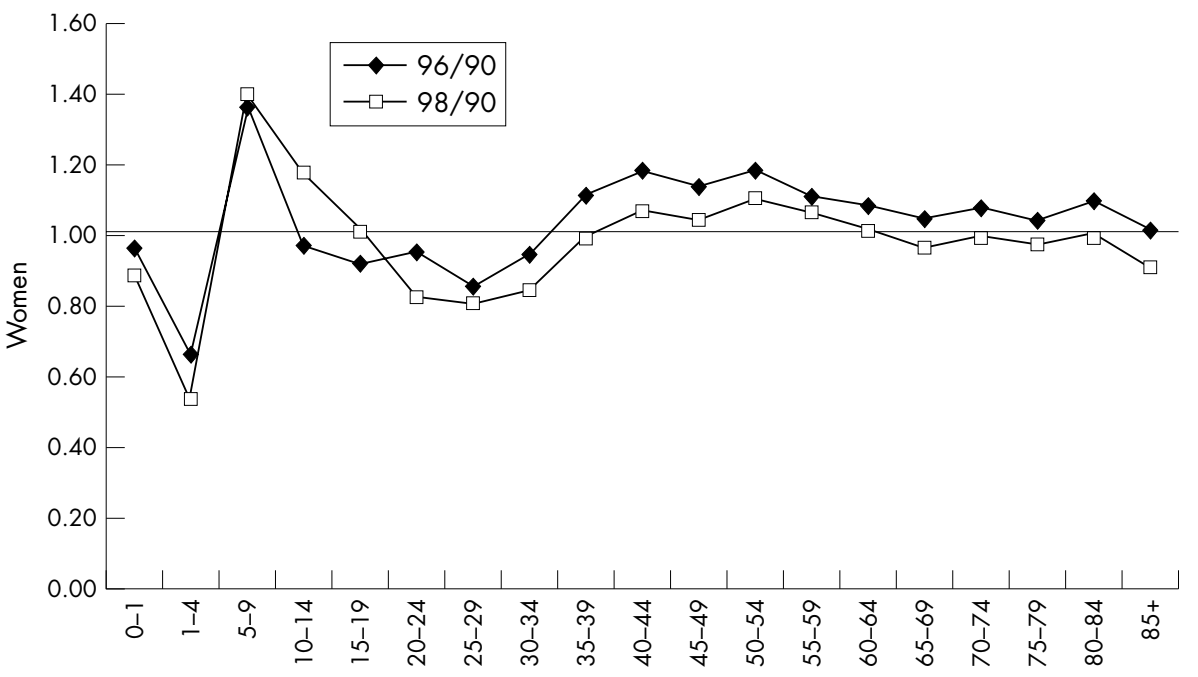


Table 1 Standardised* death rates for major causes of death, Romania, 1990-1998

\begin{tabular}{|c|c|c|c|c|c|c|c|c|c|c|}
\hline \multirow[b]{2}{*}{ Cause of death } & \multicolumn{5}{|l|}{ Men } & \multicolumn{5}{|l|}{ women } \\
\hline & 1990 & 1996 & 1998 & $96 / 90$ & $98 / 90$ & 1990 & 1996 & 1998 & $96 / 90$ & $98 / 90$ \\
\hline Infectious diseases & 19.08 & 25.78 & 22.90 & 1.35 & 1.20 & 6.35 & 6.69 & 6.58 & 1.05 & 1.04 \\
\hline Tumours & 189.55 & 217.50 & 219.19 & 1.15 & 1.16 & 117.23 & 126.45 & 127.23 & 1.08 & 1.09 \\
\hline Circulatory system & 775.18 & 928.15 & 854.58 & 1.20 & 1.10 & 645.14 & 684.29 & 628.87 & 1.06 & 0.97 \\
\hline Respiratory system & 140.59 & 124.38 & 102.97 & 0.88 & 0.73 & 78.34 & 66.11 & 51.94 & 0.84 & 0.66 \\
\hline Digestive system & 70.38 & 99.87 & 97.67 & 1.42 & 1.39 & 37.97 & 47.58 & 46.32 & 1.25 & 1.22 \\
\hline External causes & 122.31 & 125.97 & 114.20 & 1.03 & 0.93 & 38.68 & 37.68 & 34.03 & 0.97 & 0.88 \\
\hline Other causes & 76.56 & 80.05 & 75.84 & 1.05 & 0.99 & 50.33 & 50.62 & 47.32 & 1.01 & 0.94 \\
\hline All causes & 1393.65 & 1601.70 & 1487.35 & 1.15 & 1.07 & 974.04 & 1019.43 & 942.29 & 1.05 & 0.97 \\
\hline
\end{tabular}

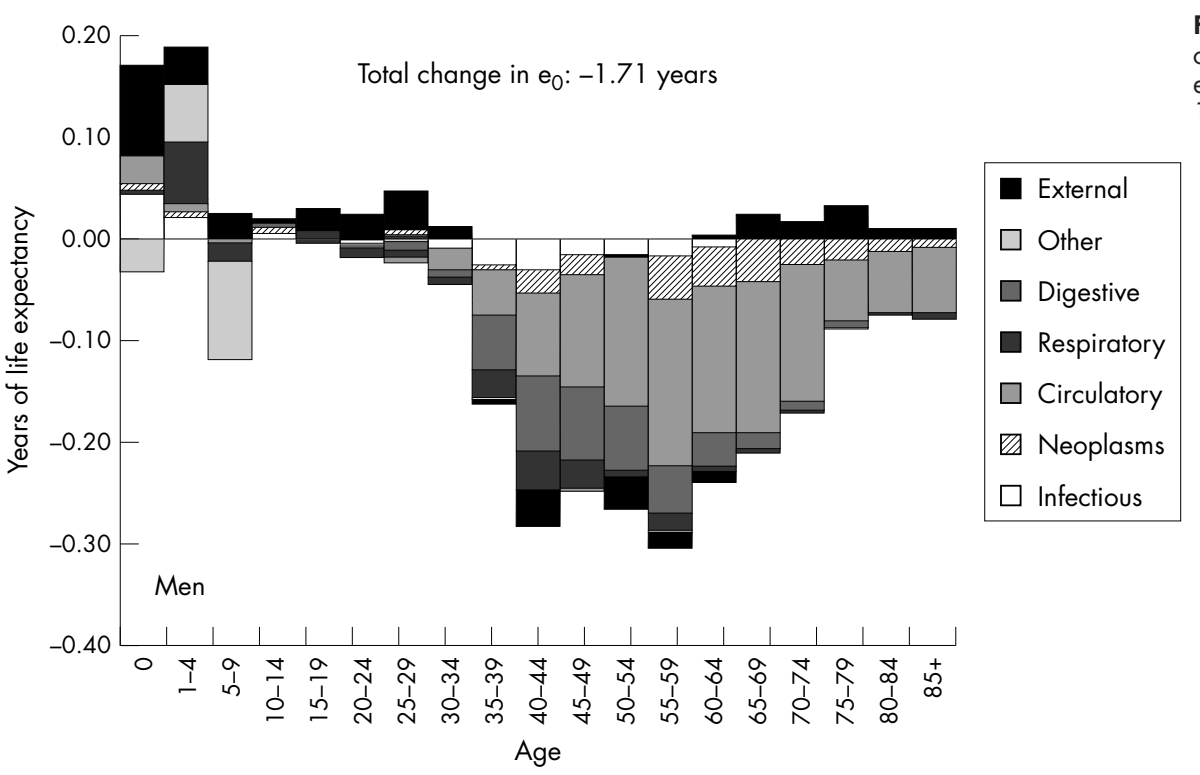

Figure 3 Contribution of age and cause of death to changes in life expectancy in Romania between 1990 and 1996.

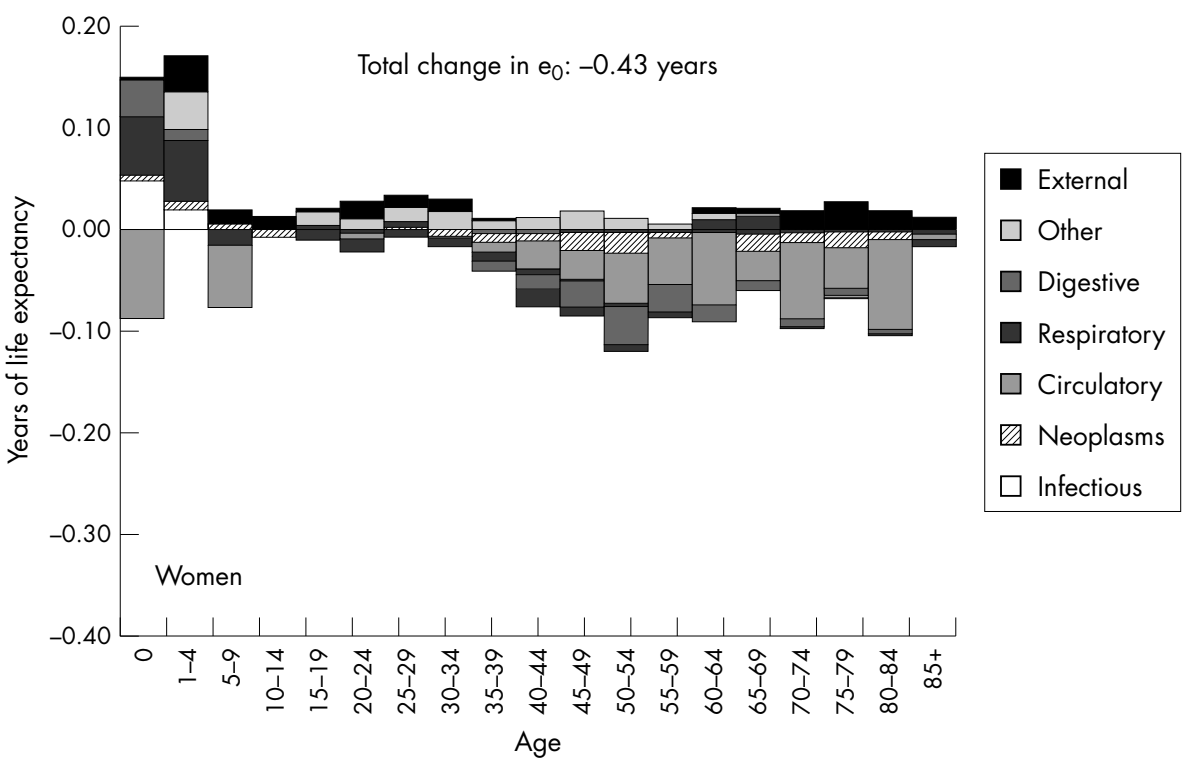

below the horizontal axis indicate that deaths in the age group and from the causes concerned contributed to a lowering of life expectancy, while those extending above the horizontal access contributed to an improvement.

Men experienced an overall decline of 1.71 years in life expectancy in 1996 compared with 1990. The largest contribution to this decrease was deaths in the 55-59 age group, at 0.30 years, followed by the age group $40-44$, contrib- uting 0.27 years. After the age of 40 , the major contributor to the decline were diseases of the circulatory system. These were closely followed by diseases of the digestive system. Had there not been a marked reduction in deaths in infancy and early childhood, the overall fall in life expectancy would have been considerably greater.

The increase in mortality in the 5-9 years age group can be seen to be attributable to "other" causes and to diseases of the 


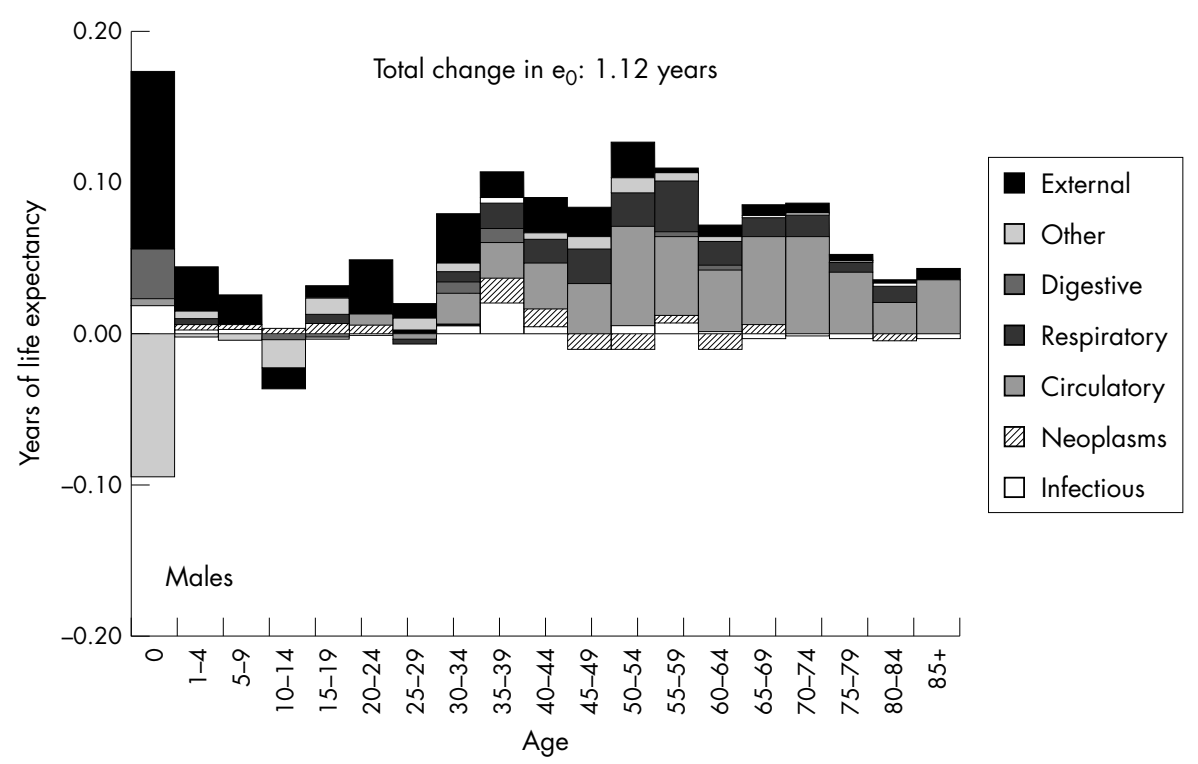

Figure 4 Contribution of age and causes of death to changes in life expectancy in Romania between 1996 and 1998.

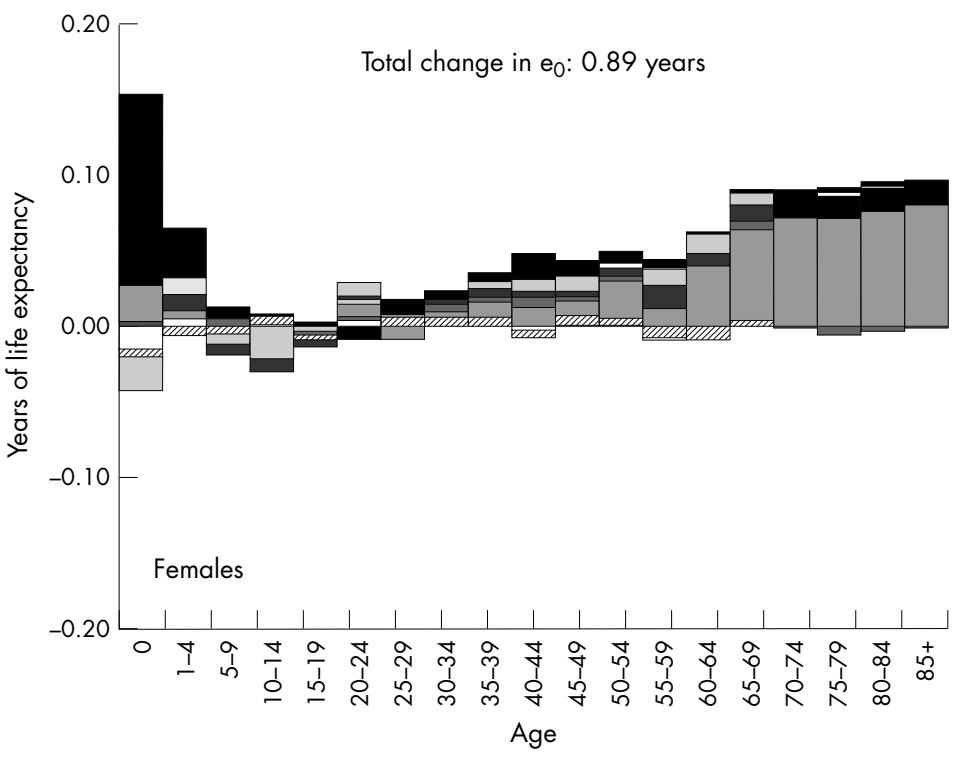

respiratory system. A closer inspection of the original data shows that this was predominantly attributable to AIDS (table 2). Thus, between 1990 and 1998, deaths per 100000 among 5-9 year olds increased by 24.9 for boys and 18.8 for girls. To identify deaths from AIDS it is necessary to be aware that, until 1996, they were coded as "other endocrine and metabolic disorders" while, after 1996, they were coded as AIDS. Increases in deaths in these two categories were greater than the overall increase in mortality in this age group, indicating that there was actually a decrease in deaths from other causes. Of course it is also possible that other AIDS related deaths were given other codes, such as respiratory disorders, but it is not possible to identify them from routine data.

The recovery between 1996 and 1998, of 1.12 years of life expectancy in men, was mainly attributable to a decline in deaths from circulatory diseases in those over 40, who contributed $31 \%$. However, the continuing improvement in infant mortality due to respiratory diseases also made a substantial contribution, of $8 \%$.

Among women, the decline of 0.43 years between 1990 and 1996 was caused substantially by an increase in mortality from diseases of the circulatory system among the elderly, with 0.22 years of life expectancy lost among women aged 55 to 74 . The recovery in life expectancy after 1996 was due

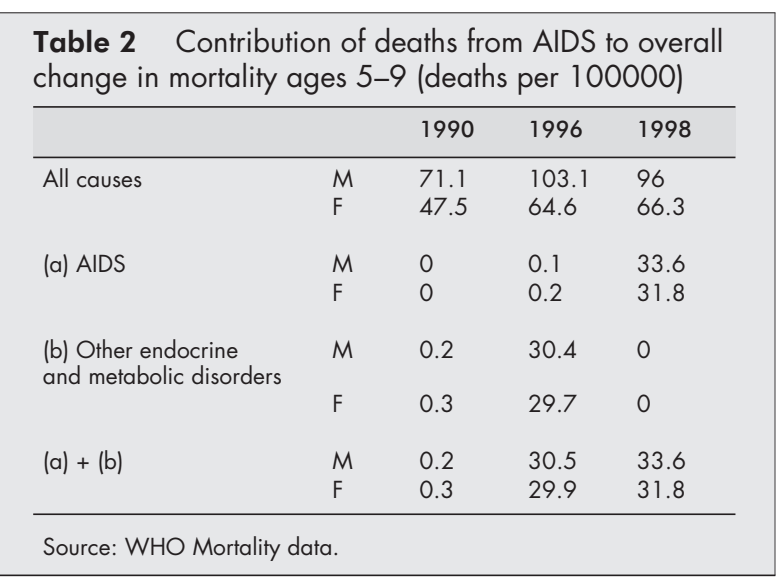

largely to reduction in mortality from circulatory diseases in the elderly, as well as a reduction in infant deaths from respiratory diseases, at about $21 \%$ and $13 \%$ respectively. However, for those aged over 75, data on cause of death should be interpreted with caution. 


\section{DISCUSSION \\ Data quality}

Before discussing the implications of this study it is necessary to explore some of its limitations. One major limitation is related to variation in death registration and certification procedures. In Romania the formal position is that all deaths must be registered, after certification by a physician. ${ }^{12}$ Necropsies are required for all accidental and sudden deaths and deaths occurring in hospital, with some exceptions, specified by law. ${ }^{13}$ However, it is estimated that $95 \%$ of deaths are medically certified and a necropsy is performed in only $7 \%$ of all deaths. ${ }^{14}$ In some rural areas, which have insufficient coverage by physicians, some death certificates are completed by nurses.

As in all countries in eastern Europe, it is necessary to consider whether migration may have played a part in observed changes, as estimates of the population denominator may not have kept pace with the true scale of movement. In 1990, there was a large net external migration, estimated to be 96900 people out of a total of 23.2 million, or $0.4 \%$ of the population, which had fallen to 19500 in $1996 .{ }^{15}$ If the scale of emigration was inadequately captured then, by inflating the true population denominator, the increase in mortality in the early 1990s would actually be slightly underestimated. Unlike some other eastern European countries, in Romania there has not been any change in the definition of a live birth and is therefore unlikely to have had an impact on observed changes in mortality. ${ }^{14}$

\section{Why was Romania different?}

As noted earlier, the evolution in life expectancy in Romania after the transition was different from that in some of its neighbours. The overall level of mortality in a population reflects a complex interplay of factors, ranging from underlying economic and political circumstances to more proximal risk factors, such as lifestyle related determinants of health.

The economic situation has emerged as an important factor in the post-transition evolution of mortality in this region. ${ }^{16-19}$ At one level this may help to explain why some Central European countries, such as the Czech Republic, Poland, and Hungary, which experienced a rapid increase in economic growth in the early 1990s, also saw an improvement in life expectancy, while Romania and Bulgaria, where the economies have stagnated, have not.

Turning to more immediate causes of death, it is necessary to consider the reasons for the large post-transition improvements seen in some other countries but not Romania. Clearly, exposure to many potential risk factors has changed, but for some the effects will only be apparent after many years. Thus, changes in smoking rates are unlikely to play a part in changing mortality in such a short time period, ${ }^{20}$ although the increases in smoking among young women in this region will obviously have a major impact in subsequent decades, and it is a matter of concern that smoking rates among Romanian physicians is so high ( $50 \%$ in men and $39 \%$ in women) ${ }^{21}$ Instead it is necessary to look at those risk factors for which changes have an impact on mortality in the short term. Falls in cardiovascular disease in Poland ${ }^{22}$ and the Czech Republic ${ }^{23}$ have been attributed to rapid changes in diet, both in relation to types of fat but, probably more importantly, in fruit and vegetable consumption. The latter is consistent with the emerging body of evidence on the importance of dietary antioxidants in the high levels of cardiovascular disease in Eastern Europe. ${ }^{24}$ Although precise dietary information is unavailable, food balance data do indicate a decline in availability from the early 1980s until 1992, after which there was a small increase, with levels remaining stable to 1998. However food balance data, which capture the net effect of imports and exports, provide a very poor measure of actual dietary availability as they exclude factors such as wastage and home production. Other

\section{Key points}

- While life expectancy in Poland, Hungary and the Czech Republic improved in the early 1990s, it deteriorated in Romania, only beginning to improve after 1996.

- The decline was attributable largely to increasing adult mortality, especially from cardiovascular diseases and diseases of the digestive system.

- The post-1996 improvement was attributable largely to a reversal of these trends.

- Romania was unique in eastern Europe in experiencing increasing child mortality after the transition.

- This was attributable almost entirely to an epidemic of paediatric AIDS, caused by a particular set of health care policies pursued in the 1980s.

evidence from industry documents confirms that the transformation of the retail food sector that has been seen in countries such as the Czech Republic was much delayed in Romania. ${ }^{25}$ It does, however, seem plausible on the basis of experience in neighbouring countries that have been examined in more detail, that changes in diet may have played a part in the post1996 improvement in deaths of the circulatory system. The immediate reasons for the deterioration between 1990 and 1996 may also have a dietary explanation but this is rather more speculative.

A second risk factor that can act over short periods is alcohol. Unfortunately, well validated data on consumption are also unavailable but a $60 \%$ increase in the death rate among men from chronic liver disease and cirrhosis between 1990 and 1996 is clear evidence that this has played a major part. This condition is the principal cause of the large increase in deaths from diseases of the digestive system, with death rates from chronic liver disease and cirrhosis increasing by $61 \%$ among men and 45\% among women between 1990 and 1996. This trend is particularly important as Romanian men have one of the highest death rates from cirrhosis in Europe, exceeded only by their neighbours in Hungary and Moldova. ${ }^{7}$ The reasons for the very high death rates in these countries, which also includes Slovenia, remain speculative. Current research is, however, exploring the role of a particular pattern of drinking in these countries, entailing heavy consumers drinking grape based products throughout most days rather than the pattern of grain based spirits drunk in binges as seen in Russia, and which leads to deaths from injuries and heart disease. ${ }^{26}$

One factor, HIV infection, has behaved in a very specific way in Romania. As we have shown, the increase in deaths among those aged 5-9 is almost entirely attributable to AIDS. In the late 1980s, over 100000 children were living in so called "orphanages" in Romania. ${ }^{15}$ "Micro-transfusions" of blood were commonly administered as treatment for anaemia or malnutrition, in many cases leading to HIV infection. Further infections arose from inadequate sterilisation of needles and syringes. ${ }^{27}$ It is probable that the death rate will fall because of the combined effect of cessation of micro-transfusions in the early 1990s and the introduction of antiviral therapy in the late 1990s. ${ }^{28}$ However, the pool of HIV positive people clearly represents a hazard in the future.

Finally, there is emerging evidence that differences in the quality of health care played a part in the east-west divide in health in the 1980s. ${ }^{1}$ There is now evidence from both the Czech Republic ${ }^{29}$ and the former German Democratic Republic $^{30}$ that improvements in perinatal care contributed to the improvement in infant mortality seen after 1990. As we note, infant mortality has declined in Romania in the 1990s, from 26.9/1000 live births in 1990 to 20.5 in 1998 and contributed significantly to the overall change in life expectancy, but this is much less than the $50 \%$ decrease seen in the Czech Republic. ${ }^{7}$ It is plausible that improved clinical facilities and, in 
particular, access to a wider range of pharmaceuticals and new ways of working may have contributed in part to the improvement that did occur among this age group. A considerable fall in the birth rate, of about 35\% between 1989 and 1996 may also have had some impact in terms of better access to intensive care facilities, similar to the Czech Republic. ${ }^{29}$

This study is a first attempt to understand why the Romanian population has not enjoyed the gains in health experienced by several of their former communist neighbours. It provides some explanations but clearly more work is needed. It is unfortunate the health needs of this country have received so little attention from researchers. While Romania has been the recipient of very large amounts of international development aid, the agencies involved have not taken time to ask why health has not improved and what might be done to change it.

It is probable that continuing economic growth will contribute to a progressive improvement in health in Romania but this will not be enough. It is obvious that much more work is needed to ascertain exactly what now needs to be done to develop an effective health policy for Romania. In particular, there is an urgent need to assess current patterns of health related behaviour, health beliefs, and levels of major risk factors. These can then be used to design and implement evidence based policies.

\section{ACKNOWLEDGEMENTS}

The authors are grateful to Dr Vladimir Shkolnikov for his contribution in developing the methodology used in this study.

\section{Authors' affiliations}

C Dolea, Department of Public Health and Management, University of Medicine and Pharmacy "Carol Davila", Bucharest, Romania

C Dolea, E Nolte, M McKee , European Centre on Health of Societies in Transition, London School of Hygiene and Tropical Medicine, London, UK

Funding: CD was supported by a fellowship from the Open Society Institute. EN was supported by a European Commission TMR Fellowship, no FMBICT983062.

Conflicts of interest: none.

\section{REFERENCES}

1 Velkova A, Wolleswinkel-van den Bosch J, Mackenbach J. The East-West life expectancy gap: differences in mortality from conditions amenable to medical intervention. Int J Epidemiol 1997;26:75-84.

2 Chenet L, McKee M, Fulop N, et al. Changing life expectancy in Central Europe: is there a single reason? J Public Health Med 1996;18:329-36.

3 Bobak M, Marmot M. East-West mortality divide and its potential explanations. BM 1996;312:421-5.
4 Shkolnikov V, McKee M, Leon D. Changes in life expectancy in Russia in the mid-90s. Lancet 2001;357:917-21.

5 Adeyi O, Chellaraj G, Goldstein E, et al. Health status during the transition in Central and Eastern Europe: development in reverse? Health Policy and Planning 1997;12:132-45

6 Nolte E, Shkolnikov V, McKee M. Changing mortality patterns in East and West Germany and Poland: short term trends during transition and in the 1990s. J Epidemiol Community Health 2000;54:889-906.

7 World Health Organisation. Health for All database. Copenhagen: WHO, 2000

8 URL. http://www.who.int/whosis/mort/dowmnload.htm

9 Waterhouse JAH, Muir CS, Correa P, eds. Cancer incidence in five continents. Lyon: International Agency for Research on Cancer, 1976.

10 Chiang CL. The life table and its applications. Florida: Malabar, 1984.

11 Arriaga E. Measuring and explaining the change in life expectancies. Demography 1984;21:83-96.

12 Legea sanitara nr. $3 / 1978$ privind asigurarea sanatatii populatiei Marea Adunare Nationala a Republicii Socialiste Romania, 1978.

13 Hotarare de Guvern nr. 774/2000. Guvernul Romaniei, 2000.

14 World Health Organisation. World Health Statistics Annual 1996. Geneva: WHO, 1998.

15 UNICEF. Education for all? Regional Monitoring Report no 5. Florence: UNICEF International Child Development Centre, 1998.

16 World Bank. World Development Report: Investing in health. New York: Oxford University Press, 1993

17 UNICEF. Crisis in mortality, health and nutrition. Regional Monitoring Report no 2. Florence: UNICEF International Child Development Centre, 1994.

18 Preker AS, Feacham RGA. Health and health care. In: Barr N, ed. Labour markets and social policy in central and eastern Europe: the transition and beyond. New York: Oxford University Press, 1994:288-321

19 Sen A. Mortality as an indicator of economic success and failure. Inaugural Innocenti Lecture. Florence: UNICEF International Child Development Centre, 1995.

20 Peto R, Lopez AD, Boreham J, et al. Mortality from smoking in developed countries 1950-2000. Oxford: Oxford University Press, 1994.

21 Didilescu C, Munteanu I. The prevalence of smoking in physicians in Romania. Pneumonologia 2000:49:91-4

22 Zatonski WA, McMichael AV, Powles JW. Ecological study of reasons for sharp decline in mortality from ischaemic heart disease in Poland since 1991. BM 1998;316:1047-51.

23 Bobak M, Skodova Z, Pisa Z, et al. Political changes and trends in cardiovascular risk factors in the Czech Republic, 1985-92. J Epidemiol Community Health 1997:51:272-7.

24 Kristenson M, Zieden B, Kucinskiene Z, et al. Antioxidant state and mortality from coronary heart disease in Lithuanian and Swedish men: concomitant cross sectional study of men aged 50. BM 1997;314:629-33

25 Romania Country Commercial Guide FY2000. URL: http://www.factbook.net/countryreports/ro/Ro_Foodmkt.htm\#Gen 26 Britton A, McKee M. The relationship between alcohol and cardiovascular disease in Eastern Europe: explaining the paradox. $J$ Epidemiol Community Health 2000;54:328-32.

27 Hersh BS, Popovici F, Apetrei RC, et al. Acquired immunodeficiency syndrome in Romania. Lancet 1991:338:645-9.

28 Kozintez C, Matusa R, Cazacu A. The changing epidemic of pediatric HIV infection in Romania. Ann Epidemiol 2000;10:474-5.

29 Koupilová I, McKee M, Holcik J. Neonatal mortality in the Czech Republic during the transition. Health Policy 1998;46:43-52.

30 Nolte E, Brand A, Koupilová I, et al. Trends in neonatal and postneonatal mortality in Germany since unification. J Epidemiol Community Health 2000;54:84-90 